\title{
(t)
}

\section{DISPARIDADES DO CRESCIMENTO GLOBAL: AVANÇOS ECONÔMICOS E ATRASOS SOCIAIS}

Disparities in global growth: economic advances and social delays

\author{
Priscila Santos Araujo ${ }^{1}$ \\ Niemeyer Almeida Filho²
}

\section{RESUMO}

A Crise do Subprime em 2007-2008 e os seus desdobramentos para as economias nacionais e o mercado internacional vêm permitindo uma nova abordagem a respeito da estrutura do capitalismo global. A abordagem consiste em discutir se alguns países em desenvolvimento, especialmente os BRICs - Brasil, Rússia, Índia e China - estariam "se descolando" do dinamismo dos países desenvolvidos. Essas proposições caminham no sentido da defesa do desenvolvimento capitalista como um processo aberto

\footnotetext{
${ }^{1}$ Graduada em Ciências Econômicas pela Universidade Federal do Espírito Santo (Ufes), Mestrado em Economia pela Universidade Federal de Uberlândia (UFU), Doutoranda em Economia pela UFU, professora do Instituto Federal do Triângulo Mineiro (IFTM) e membro do grupo de estudos: Estudos do Desenvolvimento Dependente. E-mail: <priscilasantos_eco@yahoo.com.br>.

2 Professor Associado do Instituto de Economia da Universidade Federal de Uberlândia (UFU), Pós-doutorado pela Faculdade de Economia, Administração e Contabilidade da Universidade de São Paulo (FEAUSP)/Departamento de Economia, Doutorado em Teoria Econômica pela Universidade de Campinas (Unicamp), Consultor da Coordenação de Aperfeiçoamento de Pessoal de Nível Superior (Capes) e do Instituto Nacional de Estudos e Pesquisas Educacionais Anísio Teixeira(Inep), Líder do grupo de pesquisa Desenvolvimento e Políticas Públicas do Conselho Nacional de Desenvolvimento Científico e Tecnológico (CNPq), Membro da Rede de professores de Desenvolvimento Econômico do Instituto de Pesquisa Econômica Aplicada (Ipea), Bolsista do programa Cátedras do Desenvolvimento do Ipea.
} 
ao conjunto dos países do mundo. No entanto, conforme Marini (2000), Arrighi (1996; 1998) e Santos (2004), que entendem que a economia global é estruturalmente hierarquizada, o desenvolvimento de países periféricos ou em desenvolvimento é marcado, sobretudo, pelas determinações estruturais de dependência. Existe uma relação histórica orgânica entre países subdesenvolvidos e desenvolvidos, que tende a se reproduzir a menos que ocorram alterações estruturais no comércio e na inserção internacional de todos os países. Na ausência dessas alterações, as eventuais mudanças nas participações relativas dos países no comércio, produção e fluxos financeiros globais seriam circunstanciais, sem potencial de aproximar as condições econômicas e sociais das diversas economias em um nível comum. Assim, pretendemos indicar neste artigo a existência de uma disparidade entre o crescimento econômico das economias em desenvolvimento e a manutenção de suas condições sociais precárias, acompanhadas pela menor participação relativa dos gastos do Estado para combater essas condições, que não são compatíveis com a defesa de uma mudança estrutural do desenvolvimento das economias em desenvolvimento.

\section{PALAVRAS-CHAVE}

Desenvolvimento. Dependência. Condições Sociais.

\section{ABSTRACT}

The Crisis of the Subprime in 2007-2008 and its consequences for the national economies and the international market allow a new interpretation of the structure of the global capitalism. This interpretation consists to argue if some developing countries, especially the BRICs - Brazil, Russia, India and China - would be "decoupling" with the dynamism of the developed countries. These proposals indicate the capitalist development as an open process to all of the countries of the world. However, as Marini (2000), Arrighi (1996; 1998) and Santos (2004), that they understand that the global economy is structurally hierarchized, the development of peripheral countries or in development is characterized, above all, for the structural determination of dependence. The histori- 
cal, organic relation, between underdeveloped and developed countries, tends to remain if it will not have structural changes in the trade and the international insertion of all the countries. In the inexistence of these modifications, the possible changes in the relative participation of the countries in financial trade, production and global flows would be circumstantial, without potential to approach the economic and social conditions of the diverse economies. Thus, we intend to indicate with this article the existence of a difference enters the economic growth of the economies in development and the permanence of its precarious social conditions, accompanied for the lesser relative participation of the spent of the State to fight these conditions, that are not compatible with the defense of a structural change of the development of the economies in development.

\section{KEYWORDS}

Development. Dependence. Social Conditions.

\section{INTRODUÇÃO}

A lógica de acumulação do sistema capitalista e sua evolução trazem consigo uma diferenciação do modo de desenvolvimento dos diferentes países, em termos políticos, sociais e econômicos. Esse sistema reflete uma hierarquização entre os países, ou seja, trata-se de um sistema em que os países possuem importâncias e influências distintas.

Essa perspectiva de que a economia global é estruturalmente hierarquizada é desenvolvida por Marini (2000), Arrighi (1996; 1998) e Santos (2004). Para esses autores, existe uma relação histórica orgânica entre países subdesenvolvidos e desenvolvidos, que tende a se reproduzir a menos que ocorram alterações estruturais no comércio e na inserção internacional de todos os países.

$\mathrm{Na}$ ausência dessas alterações, as eventuais mudanças nas participações relativas dos países no comércio, produção e fluxos fi- 
nanceiros globais seriam circunstanciais, sem potencial de aproximar as condições econômicas e sociais das diversas economias em um nível comum. Portanto, um possível descolamento dos crescimentos nacionais de economias em desenvolvimento e economias desenvolvidas não se apresentaria como uma possibilidade efetiva nas condições atuais.

Em contraste, a chamada Crise do Subprime, originada entre 2007 e 2008, e seus desdobramentos veem permitindo uma rediscussão a respeito da estrutura do capitalismo global. Uma das principais teses debatidas na atualidade diz respeito à crescente participação dos países em desenvolvimento na produção da riqueza e no comércio internacional. Essa abordagem é apresentada por vários autores (MORENO-DODSON et al., 2011; RODRIK, 2009; EL-ERIAN, 2009; ANDERSON, 2009; BALAKRISHNAN et al., 2009), inclusive em publicações de membros do Banco Mundial, dentre eles Otaviano Canuto, atual vice-presidente da instituição.

Otaviano Canuto, em seu artigo Recoupling or Switchover: Developing countries in the global economy, indica que há razões para sustentar que o sistema global apresenta uma nova estrutura e hierarquia, com países em desenvolvimento assumindo posições de liderança, condição até então pouco imaginada. Em parte, os elementos teóricos e empíricos utilizados por Canuto (2010) estão em Brahmbhatt e Pereira da Silva (2009), que fazem uma comparação entre a crise atual e a crise dos anos $1930^{3}$. O tema consiste em destacar que uma parcela dos países em desenvolvimento está se descolando do dinamismo dos países desenvolvidos 4 .

Essa discussão somou-se a um debate anterior, que se relaciona com a caracterização dos BRICs (conjunto de países formado por

\footnotetext{
3 Aparentemente, a avaliação da efetividade da ação dos Estados ao longo dos anos 1930 persiste como um tema polêmico. A referência feita por Canuto a esses autores é centrada na discussão da crise atual apenas, tomando os seus dados para realizar uma análise mais abrangente da crise atual.

4 Como veremos mais à frente, esta terminologia não é utilizada por autores do campo crítico da economia, que no geral preferem a menção a desenvolvidos e periféricos. Há interseções entre os grupos de países que podem ser relacionados a partir das duas terminologias, mas não identidade.
} 
Brasil, Rússia, Índia e China)5. Projeções realizadas no ano de 2001 pela Goldman Sachs (O’NEILL, 2001) já apontavam uma tendência de aumento do peso econômico desses quatro países no contexto global, no que diz respeito à população e à produção de riqueza. Da mesma forma que o debate do descolamento, o relatório formula tendências e resultados para os próximos quarenta anos, até 2050. O ponto em comum é o de firmar a posição de que o sistema global não é estruturalmente hierarquizado, admitindo mudanças a partir de circunstâncias de mercado, em uma provável direção de convergência de níveis de riqueza.

Assim, a tese que está em curso, que diz respeito a uma diminuição do hiato que separa os países desenvolvidos e os em desenvolvimento, é compatível com o discurso propalado pelos organismos internacionais - Fundo Monetário Internacional (FMI), Banco Mundial e Banco Internacional de Reconstrução e Desenvolvimento -, em especial, a partir dos anos 1970. A defesa dessas instituições é de que as reformas estruturais de abertura comercial, desregulamentação dos mercados, privatização de estatais e serviços públicos, eliminação da maior parte dos subsídios, como forma de liberalizar os preços, e a liberalização financeira interna e externa incentivariam o funcionamento dos mercados e resultariam em um reordenamento da ordem econômica.

Entendemos que essas proposições caminham no sentido da defesa do desenvolvimento capitalista como um processo aberto ao conjunto dos países do mundo, numa repetição daquilo que Celso Furtado (1980) chamou de o Mito do Desenvolvimento Econômico. De certa forma, ao sustentarem que os países em desenvolvimento assumem a primazia na definição dos rumos do capitalismo global, esses autores estão reeditando, em outros termos, a ideia de que as condições de vida dos países desenvolvidos possam ser universalizadas ${ }^{6}$.

Pretendemos mostrar neste artigo, que uma possível liderança contingente de alguns países, no que diz respeito ao dinamismo

5 Para fins deste trabalho, consideraremos apenas Brasil, Rússia, Índia e China, embora em muitos casos se incorpore a África do Sul como um quinto país desse grupo. 6 É preciso reconhecer que não há em Canuto (2010) qualquer menção à universalização das condições sociais de países como os Estados Unidos, por exemplo. O que estamos fazendo é repercutindo uma possível alteração estrutural do capitalismo global, como se fosse uma decorrência, para fins de exercício teórico. 
de suas economias no contexto global, não vem acompanhada de melhorias correspondentes no campo social, incluindo a distribuição interna da riqueza. Assim, existe uma disparidade entre o crescimento econômico e a melhoria da qualidade de vida da população dos países em desenvolvimento, em especial dos países que integram os BRICs.

O artigo está organizado em quatro seções, além desta introdução. Na primeira delas, faremos uma descrição dos termos do tema do descolamento e das mudanças estruturais do capitalismo global defendidos pelo Banco Mundial. Na segunda seção, apresentamos os argumentos teóricos que mostram, numa determinada vertente, a impossibilidade de uma alteração da estrutura do capitalismo global, a não ser por um processo revolucionário da sua hierarquia. Em seguida fazemos uma comparação de dados sociais ligados a saúde, educação e distribuição de renda entre países desenvolvidos e em desenvolvimento, para caracterizar a disparidade entre o dinamismo econômico e o social. Finalmente, apresentamos algumas conclusões.

\section{BANCO MUNDIAL: A TESE DO “DESCOLAMENTO" E AS MU- DANÇAS ESTRUTURAIS DO CAPITALISMO CONTEMPORÂNEO}

Em Canuto (2010), há dados do desempenho econômico relativo dos países em desenvolvimento e dos países desenvolvidos, para fins de análise de um possível descolamento estrutural do dinamismo dos dois grupos. A questão que orienta o trabalho é um pouco mais ampla, considerando a alternativa: descolamento ou troca de posição (decoupling or switchover).

A base de dados utilizada é o World Development Indicators (WDI) do Banco Mundial para um período que vai de 1961 a 2010, com análise de tendência até 2012. A princípio, a constatação é de que o crescimento dos países em desenvolvimento vem superando o crescimento dos países desenvolvidos desde antes dos anos 2000, porém só na última década houve uma flagrante disparidade entre os ritmos de crescimento. Além disto, afirma que no bojo da Crise do Subprime foi identificada uma característica que aparentemente reforçaria a condição já anterior, pois os países em desenvolvi- 
mento se recuperaram muito mais rápido do que os desenvolvidos. Os dados estão mostrados no Gráfico 1.



Gráfico 1 - Crescimento da Produção Mundial (\% variação) 1961-2012.

Fonte: Compilado de Canuto (2010, p.3).

A análise das projeções do produto potencial dos dois grupos reforça a tese de que há diferenças estruturais de comportamento, o que é mostrado no Gráfico 2. Há uma observação relevante para a análise de que as características apontadas não estão circunscritas ao desempenho da China e Índia, pois, em 2009, a frequência de distribuição das taxas de crescimento individuais dos países em desenvolvimento mostrava uma média bem superior à dos desenvolvidos (2,13\% em comparação a $-3,72 \%)$.



Gráfico 2 - Crescimento do PIB Potencial e Cíclico.

Fonte: Compilado de Canuto (2010, p. 3). 
Uma primeira razão apontada para este desempenho muito meIhor dos países em desenvolvimento no período de crise é o benefício de terem adotado políticas macroeconômicas melhores, além de outras políticas estruturais, pois houve capacidade de uso dos instrumentos anticíclicos das políticas monetárias, financeiras e fiscais. Ressalvam-se os casos de países que não tiveram bom desempenho pela sua excessiva integração comercial e produtiva, casos do México e países da América Central.

Seguem-se cinco outros elementos teóricos e empíricos que permitiriam sustentar uma tendência de mudança estrutural na economia global:

1. Possibilidade de maior alavancagem dos investimentos nos orçamentos públicos e balanços do setor privado: A recuperação rápida após a crise de muitos mercados emergentes grandes mostraria uma condição estrutural sólida financeira dessas economias. Os problemas financeiros das economias desenvolvidas não teriam produzido efeito na periferia (com várias exceções conhecidas - especialmente na Europa Oriental). Sugere-se que o boom na maioria dos mercados emergentes antes da crise não era organicamente dependente das condições financeiras dos países desenvolvidos. Além disso, a disponibilidade de algum espaço fiscal, bem como a existência inédita de grandes reservas em divisas e possibilidade de relaxamento monetário seria fundamental para os resultados mais favoráveis dos países em desenvolvimento (CANUTO, 2010, p. 11).

2. Convergência e uso não rival das tecnologias existentes: haveria uma condição especial de absorção de novas tecnologias desde os anos 1990, em função da abertura comercial, beneficiando países retardatários. Essas seriam tecnologias não rivais, que permitiriam a incorporação extensiva a diversas economias, alavancando os níveis de investimentos e melhorando as produtividades. Além disso, haveria potencial para a transferência de tecnologia entre os países em desenvolvimento e mesmo mobilidade para o excedente de trabaIho (CANUTO, 2010, p. 12).

3. Comércio e mudança de estrutura como aberturas para absorção de trabalho excedente: o desempenho extraordi- 
nário de algumas economias asiáticas, China em particular, seria resultado de um processo de mudança estrutural de transição ao capitalismo: o deslocamento de grandes contingentes de trabalhadores pouco qualificados de atividades estagnadas e de baixa produtividade para outros setores cujo valor a preços mundial é significativamente mais elevado e onde existe também uma ampla margem para aumentos de produtividade, estimularia o investimento e o consumo. $\mathrm{O}$ crescimento do comércio internacional e as mudanças tecnológicas teriam tornado essa mudança estrutural mais fácil (CANUTO, 2010, p. 13).

4. Trickel-down social do crescimento: após a II Guerra Mundial, Europa e Japão sofreram um ciclo longo de crescimento mediante um processo catching-up tecnológico e de consumo de massa com a fronteira dos Estados Unidos. Algo semelhante ocorreu desde a década de 1990 com muitas economias em desenvolvimento - que alcançaram elevados níveis de crescimento, facilitados por inovações em tecnologias de informação e outros campos (incluindo Finanças) - combinado com a globalização. Mantém-se um importante papel para os países desenvolvidos, que funcionaram como "[...] absorvedores desse crescimento [...]". Sustenta-se que pode ter chegado o momento de melhor correspondência dos aumentos de produção e consumo nos países em desenvolvimento aos níveis dos países desenvolvidos. Esse reequilíbrio por si só poderia tornar-se uma ferramenta poderosa para acelerar a velocidade de redução da pobreza e desigualdade. Contudo, isso não deve ser confundido com isolacionismo. Os canais para o comércio internacional e investimentos teriam que ser mantidos amplos e abertos, para que os surtos de crescimento, incluindo um eventual ressurgimento do dinamismo econômico em economias desenvolvidas, possam se complementar. Enquanto países permanecerem empenhados numa "[...] política adequada [...]" à abertura econômica, ganhos de escala e escopo podem ser ampliados, para todas as economias, independentemente do seu tamanho (CANUTO, 2010, p. 17).

5. Recursos naturais como "benção" ou trajetória de desenvolvimento: embora existam elementos para se con- 
siderar que o aumento dos preços dos produtos naturais mantenha-se nos níveis atuais (e mesmo aumentem gradualmente no médio prazo), a expectativa é de que no longo prazo ocorra um ajustamento com estabilização de preços. Portanto, não é provável um desenvolvimento pela via de primários (BRAHMBHATT; CANUTO, 2010). Contudo, com investimentos adequados e controle fiscal seriam possíveis investimentos que possam aproveitar os preços favoráveis de modo a diversificar as economias em desenvolvimento (BRAHMBHATT; CANUTO, 2010, p. 112).

Dessa análise aqui resumida, acompanhada de dados econômicos dos dois grupos de países, Canuto (2010) chega a algumas conclusões, mesmo levando em consideração que parte dos argumentos é formulada por expectativas que, para se realizar, dependeriam de boas práticas de política econômica:

The bird's eye view taken in this text leads us to conclude that, yes, there is a scope for a switchover where developing countries as a whole take on a greater role as global locomotive and move global growth forward, offsetting forces toward a negative recoupling deriving from less buoyancy in advanced countries. Nevertheless comprehensive homework in terms of domestic policies and reforms will be fundamental to accomplish that mission? (CANUTO, 2010, p. 20).

Como fica evidente pelos dados empíricos utilizados, a abordagem até aqui resumida circunscreve-se a uma concepção mais restrita do objeto da economia, limitando-se a analisar dados de desempenho produtivo da economia, implicitamente considerando que daí se determina as repercussões para o campo social. Vejamos a seguir algumas proposições teóricas que indicam a impossibilidade de ocorrer mudanças estruturais no conjunto

\footnotetext{
7 "A visão geral tomada neste texto nos leva a concluir que, sim, há uma margem para uma troca de posição completa onde os países em desenvolvimento como um todo assumam um papel maior como locomotiva global e tomem a dianteira do crescimento mundial, compensando as forças em direção a um reacoplamento negativo decorrente de um menor dinamismo nos países avançados. No entanto, trabalhar de forma abrangente em termos de políticas internas e reformas será fundamental para realizar essa missão" (CANUTO, 2010, p. 20, tradução nossa).
} 
extenso de países e alguns dados sociais para aferir se este pressuposto tem alguma validade.

\section{A TESE DA ORGANICIDADE DO SISTEMA GLOBAL: A INVIABILI- DADE DO DESCOLAMENTO SEM ALTERAÇÕES ESTRUTURAIS}

No campo crítico da Economia, o sistema global é visto como hierarquizado, compreendendo um conjunto de Estados Nacionais, que apresentam vínculos orgânicos entre si. Esta totalidade é fruto do desenvolvimento histórico do capitalismo, erigido a partir de sociedades diversas, de origem feudal ou colônias, que experimentam transições em momentos distintos. O sistema assim desenhado apresenta um núcleo central a partir do qual a dinâmica do desenvolvimento é emuladå .

A partir da perspectiva de Marini (2000), Santos (2004) e Arrighi (1996; 1998), que defendem que a economia global é estruturalmente hierarquizada, o possível descolamento de um conjunto de países teria um fôlego limitado precisamente na proporção da capacidade de autonomia relativa dos mercados internos. Além disso, uma possível liderança contingente de alguns países, no que diz respeito ao dinamismo de suas economias no contexto global, não vem acompanhada de mudanças estruturais no campo social, incluindo a distribuição interna de renda e riqueza. Segundo essa proposição, existe uma relação histórica orgânica entre países em desenvolvimento e desenvolvidos, que tende a se reproduzir. Conforme apresentado no tópico anterior, as suposições dos organismos multilaterais e agências de investimento omitem elementos fundamentais de determinação e estrutura do sistema capitalista global, particularmente aqueles relacionados à divisão internacional do trabalho.

Essas determinações estão originalmente desenvolvidas em Santos (1970, 2000) e Marini (2000) ${ }^{9}$, para os quais fica evidente

8 Esta concepção do capitalismo global é formulada, de maneira idiossincrática, por diversos autores/estudiosos do desenvolvimento capitalista: Cardoso de Mello (1982), Prado Jr (1966), Oliveira (1981), Baran (1952), Frank (1967, 1977), Santos (1970), Marini (2000), Wallerstein (1974), Furtado (1980), Harvey (2004, 2006). 9 Os autores estudam precisamente os países da América Latina, no entanto, são determinações que podem ser estendidas para as demais economias periféricas. 
que o desenvolvimento capitalista não se dá por etapas, isto é, como um caminho que basta ser trilhado para que os resultados possam ser alcançados. Assim, ao contrário do que é defendido pelo Banco Mundial, o desenvolvimento de países periféricos ou em desenvolvimento é marcado, sobretudo, pelas determinações estruturais de dependência, produto do processo histórico de sua inserção no capitalismo global.

Um ponto importante trabalhado por esses autores é que o desenvolvimento dos países da periferia está condicionado pelo desenvolvimento dos países centrais, ao tempo em que servem de base para a sua aceleração. Marini (2000) trabalha este tema, mediante o uso do conceito de superexploração da força de trabalho. Embora o argumento seja mais diretamente utilizado para interpretar as condições concretas dos países da América Latina, podemos lançar mão das ideias gerais dessa teorização para entender o desenvolvimento da periferia, mais especificamente dos países que compõem os BRICs.

Segundo Marini (2000), a partir do período colonial, a América Latina - com base na sua capacidade produtiva do trabalho e mediante uma acumulação fundada na superexploração do trabalho - foi chamada a inserir-se no mercado internacional e tornou-se auxiliadora do processo de acumulação de capital nos países centrais. Esta característica, da superexploração do trabalho, que pode ser estendida aos demais países periféricos, passa a determinar e delimitar os laços que ligam as economias periféricas à economia capitalista mundial, sobretudo aqueles laços de interesses que unem as forças sociais dominantes entre os países em desenvolvimento e os países avançados.

Marini (2000) destaca que desde os primórdios da divisão internacional do trabalho no mundo capitalista os países da América Latina inseriram-se como fornecedores de bens-salário e matérias-primas. A industrialização dos anos dourados tornou esta inserção mais diversificada, mas não a alterou na essência: a diversificação ocorreu na margem, conservando as antigas exportações e complementando-as com bens mais sofisticados. Assim, a inserção não permitiu uma dinâmica de acumulação, a essas economias, que fosse baseada no progresso técnico, exi- 
gindo depreciação dos salários, o que por sua vez determinou um mercado interno limitado.

Essa condição dos países periféricos traz decorrências singulares para o desenvolvimento das economias em desenvolvimento, já que o trabalhador é produtor e consumidor de mercadorias. $\mathrm{O}$ autor destaca que o desenvolvimento do capitalismo e a sua expansão acelerada da produção vão exigir que essa condição de consumidor seja exercida o mais amplamente possível, de modo que um nível geral de salários relativamente mais baixo funciona como o limitador de potencial; em contraste, o aumento de salários permite a aproximação do padrão de consumo dos trabalhadores do padrão de consumo capitalista, deslocando favoravelmente as demandas por produtos mais sofisticados, que são os principais aceleradores da dinâmica da acumulação.

Em uma economia em que há superexploração, esta condição não é exercida da mesma maneira que em uma economia desenvolvida. Desta forma, a natureza da acumulação vai sendo redefinida. Segundo o autor, o processo histórico de industrialização dessas economias não foi suficiente para alterar a determinação estrutural. A diversificação da industrialização encontrou seus limites na expansão do mercado interno dessas economias, engendrando um novo ciclo de exportações de bens-salário e matérias-primas, uma espécie de reiteração da inserção histórica.

Assim, para Marini (2000), após o processo de industrialização das economias periféricas, que ocorre na primeira metade do século XX, há mudanças qualitativas nessa divisão do trabalho. No entanto, não é modificado o ponto que poderia ser tomado como fulcral - a propriedade da superexploração é conservada e isto faz com que batize a ordem social da região (América Latina) como capitalismo dependente. Portanto, conforme Almeida Filho (2010), Marini, coerente com a sua motivação de apreender as condições de desenvolvimento da periferia para instrumentalizar uma ação política de transformação, indica que essa determinação estrutural só será alterada por uma ação política que reordene as economias nacionais, embora tais determinações estejam limitadas nos marcos do desenvolvimento capitalista. 
Isto indica que o sistema capitalista global é hierarquizado, ou seja, trata-se de um sistema em que os países têm importâncias e influências distintas quanto a dimensões econômica, territorial e de população (ALMEIDA FILHO, 2010). Conforme indicado anteriormente, daí decorre a existência de uma divisão internacional do trabalho entre os países/economias que fazem parte deste sistema global. A razão mais evidente para isso é que as economias que compõem este sistema dispõem de diferentes recursos produtivos, porém há ainda outros elementos que acabam por dar sustentação a um debate histórico a respeito da possível estabilidade e reprodução dessa divisão internacional do trabalho. Para o entendimento desses outros elementos, é necessário recorrer a uma qualificação relevante ao conceito da dependência que é desenvolvida pela formulação do Sistema Mundo, que, por sua vez, dá uma dimensão atualizada do aporte da dependência nos termos colocados por Marini (2000).

A formulação do Sistema Mundo busca considerar o desenvolvimento e a evolução do modo capitalista de produção como um sistema de relações econômico-sociais, políticas e culturais que nasceu no fim da Idade Média europeia e evoluiu para tornar-se um sistema planetário e confundir-se com a economia mundial. "Esse enfoque, ainda em elaboração, destaca a existência de um centro, uma periferia e uma semiperiferia, além de distinguir, dentre as economias centrais, uma economia hegemônica que articula o conjunto do sistema" (ALMEIDA FILHO, 2005, p. 7).

Conforme os teóricos do Sistema Mundo, o sistema mundial é heterogêneo em termos políticos, econômicos e culturais, abarcando grandes diferenças de desenvolvimento, acumulação de capital e poder político, entretanto, essas diferenças não são atribuídas por eles como o atraso de certas regiões em relação a outras, mas, sim, a natureza do sistema mundial, onde é inerente uma divisão da periferia, semiperiferia e centro, em função da divisão social do trabalho entre as regiões. Ou seja, a proposição é de um sistema mundial baseado em uma divisão do trabalho que une as diversas atividades espaIhadas, espacialmente, em uma economia-mundo e uma distribuição desigual do excedente entre atividades centrais e pe- 
riféricas, com concentração também diferenciada em regiões - isso permite uma analise sistêmica do capitalismo histórico ${ }^{10}$ (ARIENTE; FILOMENO, 2007).

Conforme Martins (2003), uma das mais importantes contribuições deste enfoque foi associar a economia-mundo à sua superestrutura política e avaliá-las como um sistema. A partir desta perspectiva, surgem os conceitos de Estado hegemônico, ciclos sistêmicos e tendências seculares da queda da taxa de lucro, ciclos de Kondratiev e revolução científico-técnica (MARTINS, 2003). A superestrutura da economia-mundo é o sistema interestatal, que estabelece uma assimetria estrutural entre a política e a economia que permite situar o lucro como objetivo fundamental do sistema (MARTINS, 2003).

Esse sistema é coordenado pelo Estado hegemônico que concentra a soma de poderes produtivo, comercial e financeiro necessária para instituir pela combinação de coerção e consenso um conjunto de regras que são aceitas pelos demais Estados e viabilizam o funcionamento da economia mundial em seu proveito (MARTINS, 2003, p. 201).

Outra contribuição dos teóricos do Sistema Mundo é a construção do conceito de núcleo orgânico, que compete aos países que se apropriam dos excedentes gerados nos países periféricos. Esse conceito foi desenvolvido por Arrighi (1998) em A ilusão do desenvolvimento. $\mathrm{O}$ autor, ao analisar as relações centro-periferia, explora os efeitos da divisão social do trabalho do ponto de vista internacional, dividindo o mundo inicialmente em duas jurisdições. A primeira é a jurisdição do núcleo orgânico, que tende a se tornar o lugar privilegiado onde se realizam atividades relacionadas a fluxos de inovação que a concorrência intercapitalista enseja e incluem a introdução de novos métodos de produção, novas fontes de suprimento, novas formas de organização, proporcionando ganhos extraordinários, muito acima do lucro médio proporcionado pelas atividades rotineiras. A segunda é a

10 Essa proposição de analisar o desenvolvimento desigual do capitalismo através da formação de estruturas dentro do sistema baseada nas trocas desiguais, no monopólio gerador de lucros extraordinários e da transferência do excedente suscitou críticas entre os marxistas. 
jurisdição periférica, que se subordina aos rumos determinados pela primeira jurisdição, dentro dos mesmos termos colocados pelos dependentistas. O autor, a partir do estudo da concentração de riqueza persistente na economia global dos anos 1990, mostra que existe um núcleo orgânico de países que nos últimos cinquenta anos ocuparam posições mais altas na hierarquia da riqueza global que, dado esse arranjo, estabeleceram - individual ou coletivamente - os padrões de riqueza a que todos os outros países devem almejar.

Arrighi (1998) esclarece que, quando um grupo de empresas de determinada localidade começa a inovar, elas acabam fornecendo indiretamente o poder político da jurisdição na qual operam, conferindo maior liberdade para criar um ambiente de infraestrutura econômica mais favorável, seja através da atividade inovadora, seja ocupando posições de riqueza superiores, estabelecendo, assim, os padrões de riqueza que todos os demais Estados ambicionam. Os demais países são considerados como periféricos, subordinando-se aos rumos determinados pelo primeiro grupo, exatamente nos termos colocados, como ideia, pelos dependentistas ${ }^{11}$.

Arrighi (1998) afirma que a hierarquia da riqueza dessas regiões consiste em três camadas de agrupamento distinto de acordo com a parcela de apropriação da divisão internacional do trabaIho. Os que posicionam no agrupamento superior se apropriam de uma parcela extremamente superior dos benefícios da divisão internacional do trabalho, consistindo, portanto, no núcleo orgânico do capitalismo. Já os que estão posicionados no agrupamento inferior colhem os benefícios que, no máximo, cobrem seus custos a longo prazo da participação na divisão internacional do trabalho e constituem a periferia do sistema. Existem, ainda, os semiperiféricos - grupo que se apropria dos benefícios que excedem os custos a longo prazo da participação na divisão internacional do trabalho, no entanto, isso não é suficiente para que

11 O conjunto países periféricos não corresponde aos países que estão fora o Núcleo Orgânico, pois esta referência diz respeito aos países inseridos naquilo que poderia ser tomado como o sistema capitalista global. Há países que têm uma inserção insignificante do ponto de vista de uma distribuição internacional do trabalho, como é caso de muitos países africanos. O mais apropriado, neste caso, seria referir-se a esses últimos países como países marginais, isto é, países que não têm inserção estrutural no sistema capitalista. 
seus integrantes possam manter um padrão de riqueza estabelecido pelos Estados do núcleo orgânico.

Essas três posições são definidas não apenas em termos quantitativos de apropriação de riqueza, mas também qualitativamente, no sentido de capacidades de se apropriarem dos benefícios da divisão internacional do trabalho. Os dois processos são complementares, mas são distintos. Os processos de exploração fornecem aos Estados do Núcleo Orgânico e a seus agentes os meios para iniciar processos de exclusão, que geram a pobreza necessária para induzir os dirigentes e cidadãos dos Estados periféricos e semiperiféricos a buscar, continuamente, a reentrada na divisão mundial do trabalho em condições favoráveis aos Estados do Núcleo Orgânico.

Segundo Arrighi (1998), a legitimidade e estabilidade desse sistema altamente desigual e polarizador são reforçadas pela existência de países semiperiféricos, definidos como aqueles que incluem, dentro de suas fronteiras, uma combinação mais ou menos igual de atividades de núcleo orgânico e periféricas. É justamente por essa combinação desenvolvida dentro de suas fronteiras que o autor supõe que os Estados semiperiféricos possuem poder de resistir a periferização, embora não tenham poder suficiente para superá-lo e passar a fazer parte do núcleo orgânico. Assim, os Estados podem sozinhos, conseguir cruzar o golfo que separa a riqueza modesta da semiperiferia da riqueza do núcleo orgânico, como ocorreu com o Japão e com outros países, nos últimos anos. Todavia, esses êxitos individuais ampliam o golfo para aqueles que ficam para trás, sendo inerentemente mais difícil subir de status, já que as tendências excludentes se tornam ainda mais concentradas. Assim, torna-se necessário considerar que no interior da economia capitalista mundial, por definição, os Estados não podem todos se desenvolver simultaneamente. O autor explica que o sistema funciona, justamente, graças a essa existência de regiões desiguais de núcleo orgânico e de periferia. Assim, a característica intrínseca do sistema global é a concentração de riqueza, seja na dimensão das economias nacionais, seja na dimensão das unidades de capital ou, na dimensão interpessoal. Desse modo, mesmo que ocorra um aumento de participação da periferia em relação ao núcleo orgânico, mantém-se a ideia de concentração do comando. 
Portanto, existem limites estruturais ao desenvolvimento nacional dos países em desenvolvimento, no contexto de uma ordem global capitalista. Esses limites apresentam-se em diferentes níveis ou escalas. Uma parte destes limites é comum aos países que estão fora do que Arrighi (1998) denominou de núcleo orgânico do capitalismo e parte está limitada por questões específicas de cada Estado nacional, em razão das características particulares de cada um deles.

Na ausência de alterações estruturais, as eventuais mudanças nas participações relativas dos países no comércio, produção e fluxos financeiros globais seriam circunstanciais, sem potencial de aproximar as condições econômicas e sociais das diversas economias de um nível comum. Portanto, um possível descolamento dos crescimentos nacionais de economias em desenvolvimento e economias desenvolvidas não se apresentaria como uma possibilidade efetiva, em especial, nas condições atuais ${ }^{12}$. Vejamos a seguir, se as projeções de crescimento da renda nacional, que indicam uma mudança na dinâmica dos países periféricos, conforme defendido pelo Banco Mundial (visto na segunda seção deste artigo), são acompanhadas por melhoras estruturais nas condições sociais desses países. Concentraremos nossa análise na comparação de dados entre países que compõem o Núcleo Orgânico e países que compõem os BRICs.

\section{INDICADORES DE POTENCIAL DE “DESENVOLVIMENTO SOCIAL"13}

Não há indicadores universais do desenvolvimento social dos países. O indicador contemporâneo mais utilizado para aferir a condição social dos países é o Índice de Desenvolvimento Humano

12 A conjuntura atual da natureza das inserções internacionais das economias em desenvolvimento precisa ser considerada nessa discussão. Conforme Almeida Filho (2010), a dinâmica contemporânea do sistema capitalista global tem como marca distintiva a integração, em tempo real, dos mercados financeiros nacionais, configurando virtualmente um mercado financeiro global; e isto sem uma institucionalidade supranacional que permita uma regulação global do campo das finanças. "Esta característica consolidou a hegemonia da economia americana sobre o mundo, essencialmente porque os Estados Unidos controlam a moeda mundial, o dólar" (ALMEIDA FILHO, 2010, p. 10).

13 Desenvolvimento social está entre aspas para indicar que estamos nos referindo a progresso nas condições de vida, ou ao menos de potencial de avanço dessas mesmas condições. 
(IDH). O Gráfico 3 mostra a disparidade de nível desse indicador para dois grupos de países, países considerados desenvolvidos e países em desenvolvimento. A disparidade, ou hiato, vem se mantendo no período em que os dados são disponíveis e coincide com aquele que Canuto (2010) aponta como sendo o de melhor desempenho econômico dos países em desenvolvimento. Dos Relatórios de Desenvolvimento Humano, projetam-se tendências até 2015, que mantêm a disparidade entre os dois grupos de países.



Gráfico 3 - Média do IDH por Grupo de Países - Países Desenvolvidos e Em Desenvolvimento

Fonte: PNUD (2009). Alguns poucos países não apresentam dados para o período todo, porém no conjunto são de peso insignificante.

Esta comparação também pode ser feita com países desenvolvidos selecionados e os BRICs, apresentando um hiato semelhante, não obstante o fato de que as tendências variam nas séries históricas de cada um dos países. 
TABELA 1 - Taxa de Desemprego formal por países selecionados

\begin{tabular}{|c|c|c|c|c|c|c|c|}
\hline \multirow{2}{*}{ Países } & \multicolumn{7}{|c|}{ Taxa de desemprego } \\
\hline & 1995 & 2000 & 2005 & 2006 & 2007 & 2008 & 2009 \\
\hline \multicolumn{8}{|c|}{ Países do Núcleo Orgânico } \\
\hline Austrália & 8,2 & 6,3 & 5,0 & 4,8 & 4,4 & 4,2 & 5,6 \\
\hline Austria & 3,9 & 3,6 & 5,2 & 4,8 & 4,4 & 3,8 & 4,8 \\
\hline Bélgica & 9,7 & 6,9 & 8,5 & 8,3 & 7,5 & 7,0 & 7,7 \\
\hline Canadá & 9,5 & 6,9 & 6,8 & 6,3 & 6,0 & 6,2 & 8,3 \\
\hline Dinamarca & 9,2 & 4,8 & 5,1 & 3,9 & 2,8 & 1,9 & 3,6 \\
\hline Finlândia & 15,4 & 9,8 & 8,4 & 7,7 & 6,8 & 6,4 & 8,3 \\
\hline França & 11,2 & 9,1 & 9,3 & 9,3 & 8,3 & 7,8 & 9,4 \\
\hline Alemanha & 8,0 & 7,5 & 10,6 & 9,8 & 8,4 & 7,3 & 7,5 \\
\hline Bélgica & 6,6 & 2,8 & 4,7 & 3,9 & 3,2 & 2,8 & 3,5 \\
\hline Nova Zelândia & 6,5 & 6,2 & 3,8 & 3,8 & 3,7 & 4,2 & 6,2 \\
\hline Suécia & 8,8 & 5,6 & 7,6 & 7,0 & 6,1 & 6,2 & 8,3 \\
\hline Suíça & 4,2 & 2,0 & 3,9 & 3,4 & 2,8 & 2,5 & 3,6 \\
\hline Estados Unidos & 5,6 & 4,0 & 5,1 & 4,6 & 4,6 & 5,8 & 9,3 \\
\hline Reino Unido & 8,7 & 5,5 & 4,8 & 5,4 & 5,4 & 5,6 & 7,5 \\
\hline \multicolumn{8}{|l|}{ BRICs } \\
\hline Brasil & 4,7 & 7,1 & 9,8 & 10,0 & 9,3 & 7,9 & 8,1 \\
\hline China & 2,9 & 3,1 & 4,2 & 4,1 & 4,0 & 4,2 & 4,3 \\
\hline Índia & nd & nd & nd & nd & nd & nd & nd \\
\hline Rússia & 8,5 & 10,6 & 7,6 & 7,2 & 6,1 & 6,4 & 8,4 \\
\hline
\end{tabular}

Ressalte-se que o IDH não é um índice social, o mesmo incorpora como uma de suas dimensões o Produto Interno Bruto (PIB) per capita, que traduz desempenho econômico. Melhor é utilizar um indicador de emprego formal como elemento social que advém da expansão da economia. Como se pode ver na Tabela 1, as taxas de desemprego do Brasil e da Rússia são consideradas elevadas quando comparadas com a maior parte dos países em desenvolvimento selecionados. Assim, mesmo com as projeções de crescimento, para essas economias o emprego formal continua sendo um grave problema social.

Outra dimensão importante de uma abordagem com viés social é o gasto social público. Desde o Pós Segunda Guerra Mundial, as atribuições do Estado foram ampliadas para incorporar a responsabilidade de garantir condições sociais mínimas para o conjunto 
dos cidadãos, sobretudo no que diz respeito à seguridade social e à educação. Contudo, essas responsabilidades dependem das condições financeiras dos Estados Nacionais. Não por outra razão, os países desenvolvidos apresentam níveis de gastos sociais em relação ao PIB muito maiores do que o dos demais países.

O relatório mais recente do Programa das Nações Unidas para o Desenvolvimento (PNUD) revela que a despesa pública em educação, como uma proporção do PIB, nos países desenvolvidos, é, de forma geral, significativamente superior aos gastos da Rússia, China e Índia. O Brasil, apesar de apresentar despesa pública em educação equivalente a 5,2\% do PIB - valor proporcionalmente superior ao mesmo gasto na Austrália (4,7\% do PIB), Canadá ( $4,9 \%$ do PIB) e Alemanha (4,4\% do PIB) -, apresenta resultados piores de acesso à educação. Dados de 2010 revelam que apenas $21 \%$ da população brasileira com idade superior a 24 anos alcançam, pelo menos, educação secundária. Entre 2001 e 2009, a média de taxa de matrículas no ensino superior no Brasil, na China e na Índia, situa-se em níveis significativamente inferiores aos dos países do Núcleo Orgânico do capitalismo ${ }^{14}$.

14 Núcleo Orgânico do capitalismo é um conceito de Arrighi (1998). Ele é formado pelos países desenvolvidos, na terminologia do Banco Mundial, os quais definem os rumos do capitalismo global. Esse conceito será mais bem tratado no item 4 deste artigo. 
TABELA 2 - Educação - Dados Sociais Selecionados

\begin{tabular}{|c|c|c|c|c|c|}
\hline Países & $\begin{array}{c}\text { Posição } \\
\text { no IDH } \\
2010\end{array}$ & $\begin{array}{c}\text { Despesa } \\
\text { pública em } \\
\text { Educação (\% } \\
\text { do PIB) } \\
2000-2007^{\circ}\end{array}$ & $\begin{array}{c}\text { Despesa } \\
\text { pública em } \\
\text { P\&D (\% do } \\
\text { PIB) } \\
2000-2007^{\%}\end{array}$ & $\begin{array}{l}\text { População com pelo } \\
\text { menos educação } \\
\text { secundária (\% com } \\
\text { idade superior } \\
\text { a } 24 \text { anos) } \\
2010 \\
\end{array}$ & $\begin{array}{c}\text { Taxa de matrícula } \\
\text { no ensino superior } \\
\text { (\% de população } \\
\text { em idade do nível } \\
\text { escolar superior) } \\
2001-2009^{3}\end{array}$ \\
\hline \multicolumn{6}{|c|}{ Países do Núcleo Orgânico } \\
\hline Austrália & 2 & 4,7 & 2,2 & 73,4 & 75,0 \\
\hline Nova Zelândia & 3 & 6,2 & 1,3 & 67,9 & 79,1 \\
\hline EUA & 4 & 5,5 & 2,7 & 89,7 & 81,6 \\
\hline Holanda & 7 & 5,5 & 1,8 & 67,4 & 60,1 \\
\hline Canadá & 8 & 4,9 & 2,0 & 79,6 & 62,3 \\
\hline Suécia & 9 & 6,7 & 3,7 & 80,3 & 74,5 \\
\hline Alemanha & 10 & 4,4 & 2,6 & 97,2 & - \\
\hline Suíça & 13 & 5,3 & 2,9 & 71,0 & 47,2 \\
\hline França & 14 & 5,6 & 2,1 & 55,7 & 54,7 \\
\hline Finlândia & 16 & 5,9 & 3,5 & 70,5 & 93,8 \\
\hline Bélgica & 18 & 6,1 & 1,9 & 47,7 & 62,1 \\
\hline Dinamarca & 19 & 7,9 & 2,6 & 68,1 & 80,3 \\
\hline Áustria & 25 & 5,4 & 2,5 & 70,1 & 50,3 \\
\hline Reino Unido & 26 & 5,6 & 1,8 & 58,2 & 59,0 \\
\hline \multicolumn{6}{|l|}{ BRICs } \\
\hline Rússia & 65 & 3,9 & 1,1 & - & 75,0 \\
\hline Brasil & 73 & 5,2 & 1,0 & 21,9 & 30,0 \\
\hline China & 89 & 1,9 & 1,5 & 38,4 & 22,1 \\
\hline Índia & 119 & 3,2 & 0,8 & 22,2 & 13,5 \\
\hline
\end{tabular}

Fonte: PNUD, 2010.

"Os dados referem-se ao ano mais recente disponibilizado durante o período especificado.

A análise dos dados sociais em saúde, conforme indica a Tabela 3, expõem diferenças ainda maiores. A depesa pública média em saúde, entre 2000 e 2007, alcança 3,5\% do PIB no Brasil e na Rússia, 1,1\% na Índia e 1,9\% na China. Na Alemanha e na França esse gasto chega a ser $8 \%$ e $8,7 \%$ do PIB, repectivamente. A diferença é mais expressiva quanto à mortalidade de crianças menores de 5 anos. Na Índia, a cada 1000 crianças que nasceram em 2008, 69 faleceram até os 5 anos de idade. Nos EUA, por exemplo, essas mortes não passaram de 8 . 
TABELA 3 - Dados Sociais Selecionados - Saúde

\begin{tabular}{|c|c|c|c|c|c|c|c|}
\hline Países & $\begin{array}{c}\text { Posição } \\
\text { no IDH } \\
2010\end{array}$ & $\begin{array}{l}\text { Despesa } \\
\text { pública em } \\
\text { saúde } \\
\text { (\% do PIB) } \\
2000-2007^{3}\end{array}$ & $\begin{array}{c}\text { Despesa } \\
\text { na saúde } \\
\text { per capita } \\
\text { (PPC em } \\
\text { US\$) } \\
2007\end{array}$ & $\begin{array}{c}\text { Mortalidade de } \\
\text { crianças menores } \\
\text { de } 5 \text { anos } \\
\text { (por } 1000 \text { vivos) } \\
2008\end{array}$ & $\begin{array}{c}\text { Esperança de } \\
\text { vida à } \\
\text { nescença } \\
\text { (anos) } \\
2010\end{array}$ & $\begin{array}{c}\text { Taxa de } \\
\text { Mortalidade } \\
\text { Materna (por } \\
100.000 \\
\text { nascimentos) } \\
2003-2008 \\
\end{array}$ & $\begin{array}{c}\text { População sem } \\
\text { acesso a } \\
\text { saneamento (\%) } \\
2008\end{array}$ \\
\hline \multicolumn{8}{|c|}{ Países do Núcleo Orgânico } \\
\hline Austrália & 2 & 6,0 & 3,357 & 6 & 81,9 & 4 & 0 \\
\hline Nova Zelândia & 3 & 7,1 & 2,497 & 6 & 80,6 & 9 & 0 \\
\hline EUA & 4 & 7,1 & 7,285 & 8 & 79,6 & 11 & 0 \\
\hline Holanda & 7 & 7,3 & 3,509 & 5 & 80,3 & 6 & 0 \\
\hline Canadá & 8 & 7,1 & 3,900 & 6 & 81,0 & 7 & 0 \\
\hline Suécia & 9 & 7,4 & 3,323 & 3 & 81,3 & 3 & 0 \\
\hline Alemanha & 10 & 8,0 & 3,588 & 4 & 80,2 & 4 & 0 \\
\hline Suíça & 13 & 6,4 & 4,417 & 5 & 82,2 & 5 & 0 \\
\hline França & 14 & 8,7 & 3,709 & 4 & 81,6 & 8 & 0 \\
\hline Finlândia & 16 & 6,1 & 2,84 & 3 & 80,1 & 7 & 0 \\
\hline Bélgica & 18 & 7,0 & 3,323 & 5 & 80,3 & 8 & 0 \\
\hline Dinamarca & 19 & 8,2 & 3,513 & 4 & 78,7 & 3 & 0 \\
\hline Áustria & 25 & 7,7 & 3,763 & 4 & 80,4 & 4 & 0 \\
\hline Reino Unido & 26 & 6,9 & 2,992 & 6 & 79,8 & 8 & 0 \\
\hline \multicolumn{8}{|l|}{ BRICs } \\
\hline Rússia & 65 & 3,5 & 797 & 13 & 67,2 & 28 & 13 \\
\hline Brasil & 73 & 3,5 & 837 & 22 & 72,9 & 110 & 20 \\
\hline China & 89 & 1,9 & 233 & 21 & 73,5 & 45 & 45 \\
\hline Índia & 119 & 1,1 & 109 & 69 & 64,4 & 450 & 69 \\
\hline
\end{tabular}

A desigualdade de renda é maior para o grupo de países que compõe os BRICs, conforme tabela 4. Dos países selecionados, o Brasil é o de maior desigualdade de renda. Em 2009, os 10\% mais ricos tinham uma renda 40 vezes superior aos $10 \%$ mais pobres. Nos EUA, país que possui, dentre os selecionados, índice de Gini mais próximo ao do Brasil, essa relação não chega aos 16 vezes. 
TABELA 4 - Dados Sociais Selecionados - Distribuição de Renda

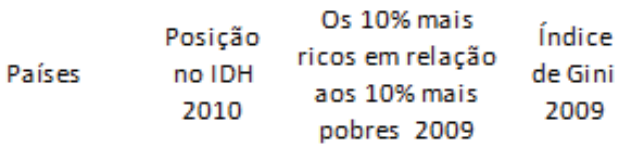

\begin{tabular}{|c|c|c|c|}
\hline \multicolumn{4}{|c|}{ Países do Núcleo Orgânico } \\
\hline Austrália & 2 & 12,5 & 35,2 \\
\hline Nova Zelândia & 3 & 12,5 & 36,2 \\
\hline EUA & 4 & 15,9 & 40,8 \\
\hline Holanda & 7 & 9,2 & 30,9 \\
\hline Canadá & 8 & 9,4 & 32,6 \\
\hline Suécia & 9 & 6,2 & 25,0 \\
\hline Alemanha & 10 & 6,9 & 28,3 \\
\hline Suíça & 13 & 9,0 & 33,7 \\
\hline França & 14 & 9,1 & 32,7 \\
\hline Finlândia & 16 & 5,6 & 26,9 \\
\hline Bélgica & 18 & 8,2 & 33,0 \\
\hline Dinamarca & 19 & 8,1 & 24,7 \\
\hline Áustria & 25 & 6,9 & 29,1 \\
\hline Reino Unido & 26 & 13,8 & 36,0 \\
\hline \multicolumn{4}{|l|}{ BRICs } \\
\hline Rússia & 65 & 11,0 & 37,5 \\
\hline Brasil & 73 & 40,6 & 55,0 \\
\hline China & 89 & 13,2 & 41,5 \\
\hline Índia & 119 & 8,6 & 36,8 \\
\hline
\end{tabular}

Fonte: PNUD, 2009 e 2010.

Numa perspectiva regional, Almeida Filho e Ortega (2009) analisam a política social da América Latina com o foco no combate à fome e à miséria. Para eles, fica evidenciado que a quase totalidade dos países dessa região não tem condição estrutural de realizar uma política social permanente, sobretudo em períodos de queda do nível de atividade, quando o gasto social poderia carregar um conteúdo anticíclico. Trata-se, portanto, de uma análise prospectiva, que aponta as dificuldades de enfretamento de questões estruturais históricas, decorrente do processo de transição ao capitalismo na região. 
Em contraste com esses números, em uma publicação do Banco Mundial que destaca o potencial de crescimento das economias periféricas, Revenga e Saavedra-Chanduvi (2010) formulam uma síntese de indicadores sociais nacionais, que revela a disparidade dos indicadores sociais entre os países desenvolvidos e os em desenvolvimento, mas concluem que a manutenção de políticas econômicas adequadas viabilizará o crescimento nas economias em desenvolvimento, ampliando o espaço fiscal necessário para a melhoria de oportunidades aos indivíduos. Com isto, espera-se uma melhora dos indicadores de desigualdade.

Poverty reduction, elimination of hunger, and equality of opportunity are essential elements of development. Growth is essential for these development objectives to be attained. The post crisis agenda requires setting the conditions for sustained growth through deeper integration into global markets and reducing factor market inefficiencies. But it also requires setting the conditions for this growth to be translated into jobs that are accessible to the poor and jobs that have increasing levels of productivity to help people move sustainably out of poverty. Growth at the same time will provide the fiscal space needed to improve equality of opportunities and give all people a chance. For growth to translate into opportunities for all, a redistributive process is critical. It entails building a social contract that is perceived by most as sufficiently fair and worth committing to both financially and politically. Equity is an essential ingredient of development, together with growth. And to make progress in the equity agenda, it is likely that the reliance on the state to foster and guide that process will have to be higher (REVENGA; SAAVEDRA-CHANDUVI, 2010, p. 21) 15.

15 "Redução da pobreza, eliminação da fome e igualdade de oportunidades constituem elementos essenciais do desenvolvimento. O crescimento é essencial para que estes objetivos de desenvolvimento sejam atingidos. A agenda pós-crise requer o ajuste das condições para um crescimento sustentado através de uma integração mais profunda nos mercados globais e redução das ineficiências de mercado. Mas também é necessário definir as condições para esse crescimento ser traduzido em empregos que são acessíveis aos mais pobres e empregos que possuem níveis crescentes de produtividade que ajudem as pessoas a saírem de forma sustentável da pobreza. O crescimento ao mesmo tempo irá fornecer o espaço fiscal necessário para melhorar a igualdade de oportunidades 




Gráfico 4 - Gasto Final do Governo em \% do PIB - Núcleo Orgânico e BRICs Fonte: International Monetary Fund (2010).

Para tanto, porém, seria necessário alterar tendências históricas, conforme pode ser visto no Gráfico 4. Nele, há comparação do nível de gasto público total das economias avançadas e as economias desenvolvidas. Há um hiato semelhante ao constatado anteriormente, neste artigo, ao do IDH, sem que existam elementos teóricos que o expliquem. As razões são políticas, portanto fora do escopo da análise. Isto indica tendência de manutenção estrutural das diferenças de intervenção política nos indicadores sociais analisados anteriormente e consequentemente das diferenças sociais.

\section{CONCLUSÃO}

A proposição de que os países em desenvolvimento estão trocando de posição com os países desenvolvidos na liderança do desenvolvimento econômico global é ideológica. Ela omite elementos fundamentais de determinação e estrutura do sistema capitalista

a todas as pessoas e ainda afetar politicamente e financeiramente. Para que o crescimento possa ser traduzido em oportunidades para todos, é fundamental um processo de redistribuição. Isso implica a necessidade de construção de um contrato social que seja percebido pela maioria como suficientemente justo. A equidade é um ingrediente essencial do desenvolvimento, juntamente com o crescimento. E, para fazer progressos na agenda da equidade, é provável que a confiança no Estado seja de grande importância para promover e orientar esse processo" (REVENGA; SAAVEDRA-CHANDUVI, 2010, p. 21). 
global, particularmente aqueles relacionados à divisão internacional do trabalho. Os países desenvolvidos e em desenvolvimento cumprem funções distintas, sendo os primeiros os definidores dos padrões de consumo e investimentos globais e os segundos mercados de consumo e fornecedores de bens de produção.

Neste artigo fizemos apenas um contraste entre duas posições que polarizam o debate a respeito das tendências que estariam em curso no desenvolvimento do capitalismo global, sem, entretanto, exercitar em profundidade os argumentos. A finalidade é mostrar que o mito do desenvolvimento ressurge em um momento em que o auge ideológico do Neoliberalismo foi deixado para trás. Aparentemente, pretende-se justificar o enorme sacrifício realizado pelos países em desenvolvimento para cumprir recomendações de política econômica que jamais foram adotadas nos países desenvolvidos.

Assim, parece-nos apropriado caracterizar as mudanças nas proposições de desenvolvimento, que orientam as ações hegemônicas capitalistas, como uma metamorfose do mito do desenvolvimento econômico. Uma mudança de natureza e forma das políticas desenvolvimentistas dos anos 1950, cujas promessas originárias, no bojo das discussões de superação do subdesenvolvimento, eram de alcance da condição social dos Estados Unidos. Celso Furtado (1980) mostrou muito bem os resultados dessas promessas: persistência da desigualdade intra e inter Estados Nacionais. Agora o mito é o da possível liderança de países periféricos. A história certamente mostrará que este futuro não é em nada mais promissor do que já foi para investigadores dos anos 1950.

A tese que pretendemos defender foi a de que a aparente tendência do crescimento nacional das economias periféricas não é entendida como uma mudança estrutural no desenvolvimento dessas economias. As disparidades das condições sociais e da participação dos gastos do Estado para combater essa condição não são compatíveis com a defesa de uma mudança estrutural do desenvolvimento das economias em desenvolvimento. A manutenção de condições sociais periféricas dos países em desenvolvimento é um fenômeno estrutural, relacionado à natureza e a respectivos dilemas do padrão de desenvolvimento capitalista dependente dessas economias. 


\section{REFERÊNCIAS}

ALMEIDA FILHO, N. O debate atual sobre a dependência. Revista da Sociedade Brasileira de Economia Política, Rio de Janeiro, v. 16, p. 32-50, 2005.

ALMEIDA FILHO, N. Os países em desenvolvimento estão se tornando desenvolvidos? In: ENCONTRO INTERNACIONAL DA ASSOCIAÇÃO KEYNESIANA BRASILEIRA, 3., 2010, São Paulo. Anais... São Paulo: AKB, 2010.

ALMEIDA FILHO, N. ; ORTEGA, J. Políticas de Segurança Alimentar Recentes na América Latina. In: ALMEIDA FILHO, N.; RAMOS, P. (Org.). Segurança alimentar, produção agrícola e desenvolvimento territorial: segurança alimentar, produção agrícola e desenvolvimento territorial. Campinas: Átomo\&Alínea, 2009, v. 1, p. 42-60.

ANDERSON, J. The Real Decoupling: UBS Emerging Economic Perspectives. Ago. 2009. Disponível em: <http:// xa.yimg.com/kq/groups/17389986/2092549030/name/UBS-The+real+decoupling.pdf $>$.

ARIENTE, W. L.; FILOMENO, F. A. Economia política do moderno sistema mundial: as contribuições de Wallerstein, Braudel e Arrighi. Ensaios FEE, Porto Alegre, v. 28, n. 1, p. 99-126, jul. 2007.

ARRIGHI, G. O longo século XX: dinheiro, poder e as origens de nosso tempo. São Paulo: Unesp, 1996.

ARRIGHI, G. A ilusão do desenvolvimento. Petrópolis, RJ: Vozes, 1998.

BALAKRISHNAN, $R$. et al. The transmission of financial stress from advanced to emerging economies. International Monetary Fund Working Paper, Jun. 2009. Disponível em: <http://www.imf.org/external/pubs/ft/wp/2009/wp09133.pdf>.

BARAN, P.A. On the Political Economy of Backwardness. In: JAMESON, K.P.; WILBER, C.K. (Eds.). The Political Economy of Development and Underdevelopment. 6. ed. New York: McGraw-Hill, 1952. p. 93-105.

BRAHMBHATT , M.; PEREIRA DA SILVA, L. The global financial crisis: comparisons with the Great Depression and scenarios for recovery. PREM Notes The World Bank, n. 141, Aug. 2009. 
Available at: <http://www1.worldbank.org/prem/PREMNotes/ premnote141.pdf $>$.

BRAHMBHATT , M.; CANUTO, O. Natural Resources and Development Strategies after the Crisis. World Bank, Washington, DC, 2010. (Economic Premise Note, 1). Originally published at: <http://siteresources.worldbank.org/EXTPREMNET/Resources/ C5TDAT_101-118.pdf>.

CANUTO, O. Decoupling, reverse coupling and all that jazz. 9 jan. 2009. Originally published at: <http://blogs.worldbank.org/growth/ decoupling-reverse-coupling-and-all-jazz>.

CANUTO, O. Recoupling or Switchover: developing countries in the global economy. 6 jan. 2010. Available at: <http://blogs.worldbank.org/growth/recoupling-or-switchover $>$.

CARDOSO DE MELLO, J. M. O Capitalismo Tardio. São Paulo: Brasiliense.

EL-ERIAN, M. A new normal. Secular Outlook, PIMCO, Mai. 2009. Available at: <https://canada.pimco.com/EN/insights/pages/secular\%200utlook\%20may\%202009\%20el-erian.aspx>.

FRANK, A. G. Dependence is dead, long live dependence and the class struggle. World Development, v.5, n. 4, April, 1977.

FRANK, A.G. Capitalism and Underdevelopment in Latin America: historical studies of Chile and Brazil. New York: Monthly Review Press, 1967.

FURTADO, C. O mito do desenvolvimento econômico. São Paulo: Círculo do Livro, 1980.

HARVEY, D. Limits to Capital. London: Verso, 2006.

HARVEY, D. O novo imperialismo. São Paulo: Loyola, 2004.

INTERNATIONAL MONETARY FUND. Data and statistics. 2010. Disponível em: <http://www.imf.org/external/pubs/ft/weo/2010/02/ weodata/index.aspx>.

MARINI, R. M. Dialética da dependência. Petrópolis: Vozes, 2000.

MARTINS, C. E. Globalização, dependência e neoliberalismo na América Latina. 2003. Tese (Doutorado em Sociologia) - Departa- 
mento de Sociologia da Universidade de São Paulo, 2003.

MORENO-DODSON, B.; BAYRAKTAR, N. How public spending can help you grow: an empirical analysis for developing countries. The World Bank Economic Primise, n. 48, Feb. 2011.

OLIVEIRA, F. Economia brasileira: crítica à razão dualista. 4. ed. Petrópolis: Vozes, 1981.

O’NEILL, J. Building Better Global Economic Brics. Goldman Sachs Economic Research Group, 2001. (The global economics paper, n.66). Disponível em: <http://www.goldmansachs.com/our-thinking/topics/brics/brics-reports-pdfs/build-better-brics.pdf>.

PNUD. Relatório de desenvolvimento humano 2009: ultrapassar barreiras : mobilidade e desenvolvimento humanos. New York: PNUD, 2009. Disponível em: <http://hdr.undp.org/en/media/ HDR_2009_PT_Complete.pdf>.

PNUD. Relatório de desenvolvimento humano 2010: a verdadeira riqueza das nações : vias para o desenvolvimento. New York: PNUD, 2010. Disponível em: < http://hdr.undp.org/en/reports/global/hdr2010/chapters/pt/ >.

PRADO JR. C. A revolução brasileira. São Paulo: Brasiliense, 1966.

REVENGA, A.; SAAVEDRA-CHANDUVI, J. Poverty, Equity, and Jobs. In: CANUTO, O.; GIUGALE, M. (editors). The day after tomorrow: a handbook on the future of economic policy in the developing world. Washington: World Bank, 2010. p. 253-274.

RODRIK, D. Growth after crisis. Presentation at the conference on Financial Crisis and its Impact on Developing Countries Growth Strategies and Prospects. Cambridge, Abr. 2009. Disponível em: $<$ http://www.iepecdg.com.br/uploads/artigos/090512_rodrik_growth_after.pdf>.

SANTOS, T. Structures of dependence. The American Economic Review, New York, p. 231-236, 1970.

SANTOS, T. A teoria da dependência: balanço e perspectivas. Rio de Janeiro: Civilização Brasileira, 2000. 
SANTOS, T. Economía mundial la integración Latinoamerica. México: Plaza Janés, 2004. v. 1.

WALLERSTEIN, I. The modern world-system, vol. I: capitalist agriculture and the origins of the European World-Economy in the sixteenth century. New York/London: Academic Press, 1974. 